\title{
Prematurity and Early Childhood Infection of Lower Respiratory Tract as Risk Factors of Developing Chronic Obstructive Bronchopulmonary Pathology in Adullts
}

\author{
DOI: $10.17691 / \mathrm{stm} 2017.9 .1 .17$
}

Received July 31, 2016

M.A. Karnaushkina, MD, PhD, Associate Professor, Department of Hospital Therapy №24:

A.D. Strutinskaya, Student;

D.Yu. Ovsyannikov, MD, DSc, Head of the Department of Pediatrics, Medical Institute ${ }^{3}$

II.M. Sechenov First Moscow State Medical University, 2/4 Bolshaya Pirogovskaya St., Moscow, 119991,

Russian Federation;

2Pirogov Russian National Research Medical University, 1 Ostrovitianov St., Moscow, 117997, Russian Federation;

${ }^{3}$ Peoples' Friendship University of Russia, 6 Miklukho-Maklaya St., Moscow, 117198, Russian Federation

The aim of the investigation was to study the impact of prematurity and severe infections of lower respiratory tract suffered in early childhood on the occurrence of chronic bronchopulmonary pathology in young adults.

Materials and Methods. 25 men took part in the study: 16 adult patients born prematurely $(n=10)$ or suffered infections of lower respiratory tract in early childhood $(n=6)$, and 9 healthy volunteers as a control group. All patients filled in British Medical Research Council (mMRC scale) questionnaires of breathlessness rating, underwent spirometry with bronchodilatation test, 6-minute walk test with determination of blood oxygen saturation level, body plethysmography and examination of lung diffusion capacity.

Results. Post-bronchodilator reversible obstruction of the peripheral airways $(p<0.05)$, signs of static hyperinflation $(p<0.05)$, and fibrous changes in the lung parenchyma $(p<0.05)$ were revealed in all participants with bronchopulmonary pathology. Though no statistically significant differences in the influence of prematurity and infections of lower respiratory tract on the function of the respiratory system have been established, structural and functional alterations in the peripheral airways were more marked in the group of prematurely born patients. Statistically significant positive correlations $(p<0.05)$ were revealed between gestation age and body mass at birth and parameters characterizing the function of the peripheral airways, as well as between the indices of static hyperinflation and the intensity of changes in the bronchi.

Conclusion. The processes affecting the growth and development of the lungs, such as prematurity and severe infection of the lower respiratory tract suffered in early childhood, result in formation of structural and functional changes of the respiratory system, which promote the development of chronic obstructive pulmonary disease.

Key words: infection of the lower respiratory tract; pulmonary consequences of prematurity; chronic obstructive pulmonary disease.

Chronic obstructive pulmonary disease (COPD) is a multiple-factor illness characterized by actually irreversible restriction of the air flow velocity. A chronic hyperergic inflammatory response of the lung parenchyma to the effect of air pollutants and infection agents underlie its development [1]. According to the WHO data, about 600 million people with COPD are living in the world at present, and nearly 11 million of them in Russia. COPD is likely to become the third cause of mortality [2].

The main etiologic factor of COPD in people over 40 years is tobacco smoking. However, in $3-11 \%$ of cases disease manifestation occurs at a younger age in non-smoking persons [3-5]. The causes of chronic bronchopulmonary pathology in the given group of patients are supposed to be such pathological factors as prematurity and a heavy course of lower respiratory tract infection (LRTI) acting in the perinatal period and during the first three years of life, and leading to the impairment of the lung growth and development [6, 7]. This supposition is based on a significant similarity of pathomorphological alterations of pulmonary tissue in the form of complete or partial occlusion of the distal airways by a fibrous tissue with the development of post-infection obliterating bronchitis in children, suffered severe LRTI, and in COPD [1, 8, 9].

A continuous growth of COPD occurrence and its revealing in people under 40 determines the interest to the study of risk factors of this ailment at the young age.

The aim of the investigation was to study the effect of prematurity and severe infections of lower respiratory tract suffered in early childhood on the occurrence of chronic bronchopulmonary pathology in young adults.

Materials and Methods. A controlled retrospective

For contacts: Dmitriy Yu. Ovsyannikov, e-mail: mdovsyannikov@yahoo.com 
Table 1

Comparative demographic and clinico-anamnestic characteristic of patients with prematurity and lower respiratory tract infection (LRTI) in the past history, and healthy persons (M $\pm m$ )

\begin{tabular}{lccc}
\hline \multicolumn{1}{c}{ Parameters } & Prematures & LRTI & Healthy \\
\hline Number of examined patients & 10 & 6 & 9 \\
\hline Mean age (years) & $21.1 \pm 2.8$ & $22.8 \pm 1.5$ & $21.2 \pm 2.2$ \\
\hline Gestation age (weeks) & $32.8 \pm 1.2$ & $39.5 \pm 1.0$ & $39.6 \pm 1.1$ \\
\hline Body mass at birth $(\mathrm{g})$ & $1910.0 \pm 484.1$ & $3583.3 \pm 511.5$ & $3600.0 \pm 405.3$ \\
\hline Prematurity in the history & Yes & No & No \\
\hline History of LRTI in early childhood & No & Yes & No \\
$\begin{array}{l}\text { Controlled pulmonary ventilation } \\
\text { in the neonatal period }\end{array}$ & Yes & No & No \\
\hline
\end{tabular}

The results of clinico-functional examination were statistically processed using Statistica 6.0 program package (StatSoft Inc., USA). Qualitative data were presented in the form of absolute or relative (\%) frequences, the quantitative data were in the form of $\mathrm{M} \pm \mathrm{m}$ ( $\mathrm{M}$ - arithmetic mean, $\mathrm{m}-$ standard deviation). To assess the differences of the means in pairwise independent samples, Mann-Whitney U-test was used, in several independent samples Kruskal-Wallis H-test was applied. Differences were considered significant at $p<0.05$. Correlation analysis was performed using Spearman's coefficient of rank correlation.

Results and Discussion. Data of the comparative intergroup analysis of clinicostudy "case-control" was carried out, which included 16 patients born prematurely or suffered LRTI in early childhood, and 9 healthy volunteers who composed a control group. There were 17 men and 8 women among the examined patients, the average age being $21.6 \pm 2.3$ years. People in the control group did not have heavy somatic, chronic bronchopulmonary pathology in the past history, and did not smoke.

The study complies with the Declaration of Helsinki (the Declaration was passed in June 1964, Helsinki, Finland, and revised in October 2000, Edinburg, Scotland) and was performed following approval by the Ethic Committee of Peoples' Friendship University of Russia. Written informed consent was obtained from every patient.

According to the first-visit history data patients were stratified into two groups. Group 1 (patients born prematurely) comprised 10 patients with gestation age less than 37 weeks. Group 2 (LRTI) included 6 people suffered severe LRTI required hospitalization in early childhood (Table 1). The stratified groups were comparable by the age and gender.

After filling in the British Medical Research Council (mMRC scale) questionnaire of breathlessness rating and physical examination, all patients were performed spirometry with bronchodilatation test, 6-minute walk test (6MWT), determination of blood oxygen saturation level before and after 6MWT, body plethysmography and examination of lung diffusion capacity [10]. Respiratory functional diagnosis was carried out according to the standard protocol of the European Coal and Steel Community [11] using MasterScreen Body equipment (Erich Jaeger, Germany). The data obtained were compared with the reference values calculated with the help of the formulas given in the mentioned protocol. Organs of the thoracic cavity of all patients were examined using multispiral computed tomography (MSCT) with functional tests conducted by means of Somatom Sensation 40 CT Scanner (Siemens, Germany). functional parameters in the examined patients (Table 2) demonstrate that persons with prematurity and LRTI in the past history differ statistically significantly $(p<0.05)$ from the healthy volunteers by the number of bronchitis which they had for the previous year $(1.60 \pm 1.17$, $1.67 \pm 1.21$ and $0.22 \pm 0.44$, respectively). The indices of the forced expiratory volume in 1 second (FEV1) prior to the test with a broncholytic in patients of the premature group were estimated to be significantly lower $(79.40 \pm 2.73 \%$ of the reference value; $p<0.05)$ relative to the LRTI group $(83.40 \pm 5.44 \%$ of the reference value) and the group of healthy people $(91.2 \pm 4.6 \%$ of the reference value).

Values of the parameters characterizing peripheral airway function were evaluated. Forced mid-expiratory flow between 25 and $75 \%$ of forced vital capacity $\left(\mathrm{MEF}_{25-75}\right)$ in patients of the experimental groups was also significantly lower $(p<0.05)$ than in the control group $(70.1 \pm 5.2,72.2 \pm 3.9$ and $83.8 \pm 4.6 \%$, respectively), as well as the momentary forced expiratory flow at $75 \%$ of forced vital capacity $\left(\mathrm{FEF}_{75}\right)(70.2 \pm 5.8,71.3 \pm 2.7$ and $80.9 \pm 2.4 \%$ of the reference value, respectively) (See the Figure). The data obtained may testify to the obstruction mainly in the distal parts of bronchi which is confirmed by statistically significant rise of the residual lung capacity in the experimental groups in comparison with the healthy volunteers $(103.60 \pm 11.06,107.0 \pm 10.24$ and $94.30 \pm 7.19 \%$ of the reference values, respectively). Besides, in 9 cases from both groups of patients with bronchopulmonary pathology $(n=16)$ the signs of "air traps" were found according to MSCT data. Indices of residual lung capacity and MSCT data gave evidence of the signs of static hyperinflation.

In addition to "air traps", such alterations in the pulmonary tissue as bullas, areas of linear fibrosis and thickening of bronchial walls were confirmed in 11 patients of the experimental groups by means of MSCT.

Attention should be paid to the fact that patients in the group of prematures and LRTI did not have statistically significant differences in the main clinico-functional 
Table 2

Clinico-functional parameters in patients with prematurity and lower respiratory tract infection (LRTI)

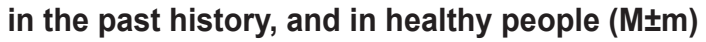

\begin{tabular}{|c|c|c|c|}
\hline Indices & Prematures $(n=10)$ & LRTI $(n=6)$ & Healthy $(n=9)$ \\
\hline Bronchitis in the previous 12 months (number of episodes) & $1.60 \pm 1.17$ & $1.67 \pm 1.21$ & $0.22 \pm 0.44^{v}$ \\
\hline 6MWT (m) & $511.5 \pm 48.9^{+}$ & $560.8 \pm 66.7$ & $724.4 \pm 41.9^{v}$ \\
\hline FEV1 (\% of the reference value prior to bronchdilatation test) & $79.4 \pm 2.7^{\star+}$ & $83.4 \pm 5.4$ & $91.2 \pm 4.6^{v}$ \\
\hline FEV1 (\% of the reference value after bronchodilatation test) & $88.8 \pm 5.7$ & $88.8 \pm 4.8$ & $92.3 \pm 5.2$ \\
\hline $\mathrm{MEF}_{25-75}(\%$ of the reference value $)$ & $70.1 \pm 5.2^{+}$ & $72.2 \pm 3.9$ & $83.8 \pm 4.6^{v}$ \\
\hline $\mathrm{FEF}_{75}(\%$ of the reference value) & $70.2 \pm 5.8^{+}$ & $71.3 \pm 2.7$ & $80.9 \pm 2.4^{v}$ \\
\hline $\mathrm{SatO}_{2}$ after $6 \mathrm{MWT}(\%)$ & $97.1 \pm 1.8$ & $97.5 \pm 1.5$ & $98.4 \pm 0.5$ \\
\hline Residual volume (\% of the reference value) & $103.6 \pm 11.1^{+}$ & $107.0 \pm 10.2$ & $94.3 \pm 7.2^{v}$ \\
\hline Residual capacity (\% of the reference value) & $101.3 \pm 9.1^{+}$ & $90.3 \pm 10.4$ & $85.4 \pm 3.7$ \\
\hline "Air traps" according to MSCT data (\% of the examined patients) & $60^{+}$ & 50 & 0.0 \\
\hline Bulls, according to MSCT data (\% of the examined patients) & 20 & 33.3 & 0.0 \\
\hline Thickening of bronchial walls according to MSCT data ( $\%$ of the examined patients) & 50 & 16.7 & 0.0 \\
\hline$D_{L C O}(\%$ of the reference value) & $90.6 \pm 6.2$ & $97.7 \pm 11.9$ & $93.4 \pm 7.4$ \\
\hline
\end{tabular}

$\mathrm{N}$ o t e . 6MWT: 6 minute walk test; FEV1: forced expiratory volume in 1 second; MEF $_{25-75}$ : forced mid-expiratory flow between 25 and $75 \%$ of forced vital capacity; $\mathrm{FEF}_{75}$ : momentary forced expiratory flow at $75 \%$ of forced vital capacity; SatO $_{2}$ : oxygen saturation; MSCT: multispiral computed tomography; $\mathrm{D}_{\mathrm{LCO}}$ : diffusing capacity of the lung for carbon monoxide. * Statistically significant differences between the groups of prematures and LRTI $(p<0.05) ;{ }^{+}$between the groups of prematures and healthy persons $(p<0.05) ;{ }^{v}$ between the groups of LRTI and healthy persons $(p<0.05)$.

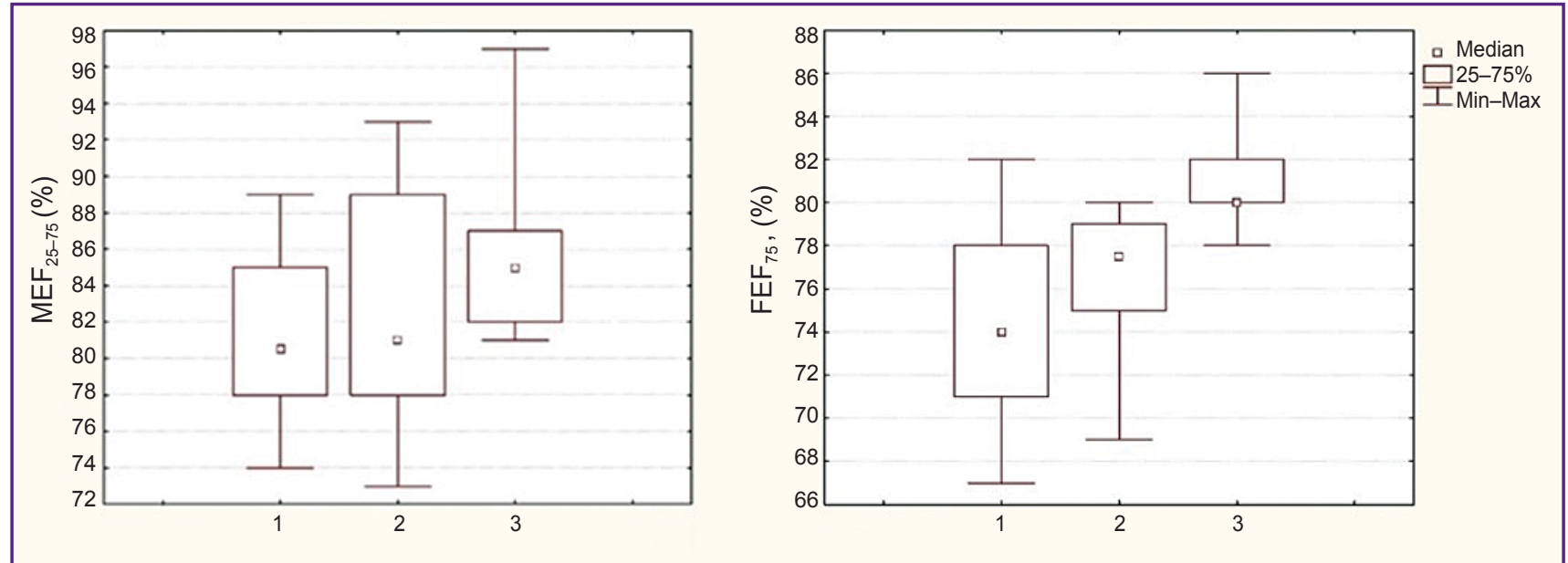

Diagram of the index range for $\mathrm{MEF}_{25-75}$ and $\mathrm{FEF}_{75}(\mathrm{p}<0.05)$ in the groups of patients with prematurity $(1)$, lower respiratory tract infection (2), and healthy volunteers (3): comparison of the three groups using Kruskal-Wallis H-test. The data are presented in the form of median/quart/range

criteria excluding FEV1 index. Nevertheless, values of $\mathrm{FEV} 1, \mathrm{MEF}_{25-75}, \mathrm{FEF}_{75}$ after the test with broncholytics were lower in prematures than the similar values in LRTI group, though they did not reach the degree of statistical significance. This fact and bronchial wall thickening revealed by MSCT in half of the prematures (and only
1 of 6 in LRTI group) can be the evidence of more pronounced morphofunctional changes in the airways of these patients.

Analysis of correlations between the anamnestic and clinico-functional indices was carried out using Spearmen's coefficient of rank correlation. Statistically 
Table 3

Gestation age, body mass and associated with them clinico-functional indices in adults born prematurely or suffered severe infection of the lower respiratory tract in early childhood

\begin{tabular}{lcc}
\hline \multicolumn{1}{|c}{ Parameters } & $\begin{array}{c}\text { Body mass } \\
\text { at birth (p) }\end{array}$ & $\begin{array}{c}\text { Gestation } \\
\text { age }(\mathbf{p})\end{array}$ \\
\hline $6 \mathrm{MWT}$ & 0.000199 & 0.000462 \\
\hline FEV1 & 0.001773 & 0.000350 \\
\hline $\mathrm{MEF}_{25-75}$ & 0.033967 & 0.000330 \\
\hline Residual capacity & 0.014031 & 0.000614 \\
\hline $\begin{array}{l}\text { Thickening of the bronchial } \\
\text { walls according to MSCT data }\end{array}$ & 0.024526 & 0.023360 \\
\hline
\end{tabular}

N o t e. 6MWT: 6-minute walk test; FEV1: forced expiratory volume in 1 second; MEF25-75: forced mid-expiratory flow between 25 and $75 \%$ of forced vital capacity; MSCT: multispiral computed tomography.

significant differences with the values of the confidence coefficient $p<0.05$ are presented in Table 3 . Statistically significant positive correlations of gestation age and body mass at birth with tolerance to physical load, FEV1, parameters characterizing the function of the peripheral airways $\left(\mathrm{MEF}_{25-75}\right.$ and $\left.\mathrm{FEF}_{75}\right)$, indices of static hyperinflation (pulmonary residual volume, residual capacity, "air traps") and intensity of alterations in the bronchi were found in the examined patients.

There has long been existing an opinion that in children born prematurely the decrease of incidence and intensity of respiratory manifestations is observed as they grow up. However, the data of long-term investigations [12-14] and the results of the present work, being in accord with them, have proved preservation of respiratory function impairment of obstructive type and morphological alteration of the peripheral airways, confirmed by MSCT, as children with this risk factor in the past history grow up. Thus, in case of prematurity, as well as after severe LRTI in early childhood patients are liable to forming a COPDlike phenotype, since the impairments found in the bronchopulmonary system are similar to those in COPD $[1,15]$. This fact convincingly proves the contribution of prematurity and early-childhood LRTI to the development of chronic bronchopulmonary pathology.

Detailed study of COPD formation and its clinical course in young non-smoking adults and detection of risk factors of its development will make it possible to work out preventive measures (for example, courses of respiratory rehabilitation for children born prematurely or suffered heavy LRTI in their early childhood) and new approaches in the management of this cohort of patients.

Conclusion. The conducted study has revealed the impact of prematurity and early-childhood LRTI on the clinico-functional condition of the respiratory system in adults. However, the data are not reliable which is likely to be due to a small sample volume. This dictates the necessity of continuing the work in this direction, carrying out prospective investigations and patients follow-up.

Study Funding. This study was not supported by any financial sources.

Conflict of Interests. The authors have no conflict of interests related to this study.

\section{References}

1. Global Strategy for Diagnosis, Management and Prevention of COPD (2016 update). URL: http://www. goldcopd.org.

2. World Health Report 2003. URL: http://www.who.int/ whr/2003/en/whr03_en.pdf.

3. Chilvers E.R., Lomas D.A. Diagnosing COPD in nonsmokers: spitting not lumping. Thorax 2010; 65(6): 465-466, https://doi.org/10.1136/thx.2009.128421.

4. Eisner M.D., Anthonisen N., Coultas D., Kuenzli N., Perez-Padilla R., Postma D., Romieu I., Silverman E.K., Balmes J.R.; Committee on Nonsmoking COPD, Environmental and Occupational Health Assembly. An official American Thoracic Society public policy statement: novel risk factors and the global burden of chronic obstructive pulmonary disease. Am J Respir Crit Care Med 2010; 182(5): 693-718, https://doi.org/10.1164/rccm.200811-1757st.

5. Lamprecht B., McBurnie M.A., Vollmer W.M., Gudmundsson G., Welte T., Nizankowska-Mogilnicka E., Studnicka M., Bateman E., Anto J.M., Burney P., Mannino D.M., Buist S.A.; BOLD Collaborative Research Group. COPD in never smokers: results from the population-based burden of obstructive lung disease study. Chest 2011; 139(4): 752-763, https://doi.org/10.1378/chest.10-1253.

6. Tennant P.W., Gibson G.J., Parker L., Pearce M.S. Childhood respiratory illness and lung function at ages 14 and 50 years: childhood respiratory illness and lung function. Chest 2010; 137(1): 146-155, https://doi.org/10.1378/ chest.09-0352.

7. Svanes C., Sunyer J., Plana E., Dharmage S., Heinrich J., Jarvis D., de Marco R., Norbäck D., Raherison C., Villani S., Wjst M., Svanes K., Antó J.M. Early life origins of chronic obstructive lung disease. Thorax 2010; 65(1): 14-20, https://doi.org/10.1136/thx.2008.112136.

8. Bojcova E.V., Zapevalova E.Yu., Ovsyannikov D.Yu. Respiratory, neurological and structure-functional sequellae of bronchopulmonary dysplasia in children and adults. Neonatologiya 2014; 1(3): 71-79.

9. Bojcova E.V., Ovsyannikov D.Yu. Chronic bronchiolitis in children and adolescents. Pediatriya 2014; 3: 118-124.

10. Fletcher C.M. The clinical diagnosis of pulmonary emphysema; an experimental study. Proc $R$ Soc Med 1952; 45(9): 577-584.

11. Quanjer P.H., Tammeling G.J., Cotes J.E., Pedersen O.F., Peslin R., Yernault J.C. Lung volumes and forced ventilatory flows. Report Working Party Standardization of Lung Function Tests, European Community for Steel and Coal. Official Statement of the European Respiratory Society. Eur Respir J 1993; 6(Suppl 16): 5-40, https://doi. org/10.1183/09041950.005s1693.

12. El Mazloum D., Moschino L., Bozzetto S., Baraldi E. Chronic lung disease of prematurity: long-term respiratory 
outcome. Neonatology 2014; 105(4): 352-356, https://doi. org/10.1159/000360651.

13. Ovsyannikov D.Yu. Treatment and prevention of bronchopulmonary dysplasia: from pathogenesis to evidencebased medicine. Voprosy prakticheskoy pediatrii 2009; 4(4): 30-41.

14. Neptune E.R. Chronic obstructive pulmonary disease and bronchopulmonary dysplasia: common mechanisms but distinct manifestations? Pediatr Allergy Immunol Pulmonol 2011; 24(2): 119-125, https://doi.org/10.1089/ped.2011. 0072.

15. Hilgendorff A., O'Reilly M.A. Bronchopulmonary dysplasia early changes leading to long-term consequences. Front Med 2015; 2, https://doi.org/10.3389/fmed.2015.00002. 